\title{
The Effect of Educational Program on Status Care in Patients with Tracheostomy and Families' Anxiety After Discharge
}

Salehi Shiva ${ }^{1 *}$, Tabarsy Beheshte ${ }^{2}$ and Moghtader Osmavandani Maria ${ }^{2}$

${ }^{1}$ Tehran University of Medical Sciences, Tehran, Iran

2Islamic Azad University, Tehran Medical Branch, Tehran, Iran

"Corresponding author: Salehi Shiva, Faculty of Public Health, Tehran University of Medical Sciences, Tehran, Iran, Tel: +989124752190; E-mail: salehi.shiva@yahoo.com

Received date: December 06, 2017; Accepted date: December 14, 2017; Published date: December 21, 2017

Copyright: @ 2017 Shiva S, et al. This is an open-access article distributed under the terms of the Creative Commons Attribution License; which permits unrestricted use; distribution; and reproduction in any medium; provided the original author and source are credited.

\begin{abstract}
Introduction: Diseases and their pertained treatments are of the major cases led to suffering from anxiety. Anxiety, in fact, is an informing process and influences the quality of life of patients and their families and endangers their improvement in case of being continued. Tracheostomy is one of the methods creating artificial air passage and it will be superior over other techniques and performed for a long time in case of needing the artificial air passage. Caring patients with Tracheostomy is very important and stressful; the anxiety of families can deeply influence their ability in decision making and causes the decrease of care skills and their performance in caring patients. Considering the importance of the issue, the purpose of the present study has been to evaluate the changes resulted by the components of educational program provided for patients' families to improve their performance and decrease their anxiety after discharge in 2012-2013.
\end{abstract}

Materials and methods: As a quasi-experimental study, 31 patients in hospitals of Gilan Province have been investigated. The sample has been selected using judgmental sampling method. To gather required data, questionnaire (to evaluate demographic characteristics and Spill Berger anxiety scale) and checklist of families' skill and performance in caring patients have been employed. The results obtained from performing educational program were recorded and compared with before the education. The obtained data was analysed through SPSS software.

Results: As the research findings revealed, the mean and standard deviation of total anxiety were $112.35 \pm 16.18$ and $95.8 \pm 13.07$ before and after performing educational program, respectively. In other words, there is a significant relation between total anxiety before and after the educational program, the mean of total anxiety was significantly decreased $(P=0.0001 ; t=16.29)$ and the mean and standard deviation of care skill and total performance of the sample was significantly increased from $93.7 \pm 6.57$ to $119.8 \pm 7.2$, indicating that the performance and care skill of the sample was significantly improved $(P=0.0001)$.

Conclusion: Finally, the research results showed that implementing educational program causes the decrease of anxiety and the increase of the skill of families of the patients with Tracheostomy.

Keywords: Anxiety; Educational program; Care skill and family performance; Tracheostomy

\section{Introduction}

Today, increasing pressure of tension and anxiety-causing factors has been followed by unpleasant results for human [1]. In addition to physical interactions, most of human show mental reactions but the interaction experienced by many people is anxiety [2]. Diseases and their pertained treatments are of the major cases led to suffering from anxiety [3].

Anxiety can be resulted in many effects on family including changes in performance, behaviour and emotions, role of family and its dynamic, and self-concept [4]. Although mild anxiety can encourage individuals to learn changing life style, intense anxiety can be almost crippling and lead to the decrease of the family performance in caring patients, lengthening confinement duration, spending high costs due to frequent references, and postponing patients' recovery [5].
In a research conducted in 2005, 544 families of confined patients were studied in French and it was found that $75.5 \%$ of the patients' families had anxiety and $82.7 \%$ of them were the patients' spouses [6].

Meanwhile, it is necessary to consider the role of nurses and their interventions and training caring patients with respect to the type of disease to prevent anxiety in the family of confined patients [7]. Educational program means every pre-planned activity or decision with the aim of creating learning in individuals and creating changes in their behaviours [8]. Confining one of the family members can cause anxiety and mental problems, particularly if the patient is confined in stressful wards such as ICU or emergency ward [9].

Teaching is an interactive process promoting learning and including a set of intelligent and precise efforts that help individuals to achieve new knowledge, change their attitude, accept new behaviour's, or perform new skill [10].

A nurse should teach appropriate behaviour's to patients and their families to care and treat diseases [11]. A comprehensive educational program which is appropriate with learning needs of patients and their 
families can decrease the costs of caring and improve the quality of caring [12].

Nurses should emotionally support families of patients and decrease their anxiety and help families in decision making about caring patients and performing it after discharge $[13,14]$.

Continuously teaching nurses help families of patients with Tracheostomy to increase confidence and decrease anxiety during caring the patients, leading to the increase of families' performance and ability in caring patient and decreasing the probable side effects of Tracheostomy [15].

According to Indian and Egyptian texts, Tracheostomy has been used to save patients with respiratory problems for a long time [16].

Tracheostomy is to create an opening in neck which is commonly performed to supply air passage in patients with upper system obstruction and maintain larynx in patients through placing a tube in the opening for a long time [17]. The main items taught to these patients include caring Tracheostomy pipe, considering two lesions of bloodshed and infection, the way of lung secretions suction, oxygen therapy, chest physiotherapy, and observing mouth and tooth health [18].

In 2006, a study was performed on $70 \%$ of patients confined in ICU in Switzerland. In this study, most of Tracheostomy techniques were performed in the second week of confinement with the frequency of $60 \%$. In most of the samples, $69 \%$ of Tracheostomy was performed through bypass and $57 \%$ in the form of percutaneous [19].

Another research carried out in Germany (2008) showed that tracheostomy was performed in $90 \%$ of patients confined in ICU during the first fourteen days of confinement, particularly in the second week [20]. In Iran, it has been reported that in $24 \%$ of patients confined in ICU, Tracheostomy was performed during the first fourteen days and the most important indication of Tracheostomy in different studies is avoiding placing pipe for long time [21].

According to the studies, total amount of Tracheostomy side effects' incidence is $49 \%$ and its resulted death is $2 \%$ [22]. Caring patients with Tracheostomy in home can be successfully performed. In caring patients with Tracheostomy, family, as the first and most fundamental social entity plays a significant role and should be able to play emotional, educational and physical role [23].

According to the report of medical documents unit (2011), in Pour Sina Hospital in Rasht which is the only Trauma Center of Gilan Province, 150 patients (out of 714 patients) were subjected to Tracheostomy surgery and due to head trauma and the decrease of consciences level, most of them need to long-term ventilation and are discharged with consciousness level of 8 to 10 . The family of these patients suffers from a high level of anxiety, leading to disturbance in their performance in caring patients and frequently referring to hospital, and spending high cost. Therefore, this study has attempted to decrease the anxiety of families of patients with Tracheostomy and subsequently, improve their performance in caring patients leading to accelerating the improvement of their patients [24].

Investigating 47 nurses in Canada (2007), a quasi-experimental study was performed entitled the role of nurses regarding the families of patients confined in ICU. As found, nurses who communicated with the families of patients and help them in caring had a feeling of being usefulness and calmness [25].
Again, a descriptive study titled the analysis of the effect of teaching based on the need of families of patients confined in ICU in Hong Kong investigated 34 people. As revealed, there is a need of comprehensive evaluation of mental and social needs of family members to plan appropriate interventions to decrease their stress [9].

In another quasi-experimental study, 84 people of the main attentive and families were investigated the effect of teaching caring patients suffering from brain damages on mental health of attentive after discharge in Mashhad. As it was concluded, the level of information and mental health of attentive after discharge compared to before the treatment at all scales (physical disorder, anxiety, depression, and social performance) was significantly improved $(\mathrm{P}<0.005)[26]$.

The present study has attempted to evaluate the changes resulted by educational program for the families of patients after discharge to decrease their anxiety and increase their care skills after discharge.

\section{Methodology}

The present research was a quasi-experimental study investigating 31 patients confined in neurosurgery ward of Pour Sina Hospital in Rasht. The patients with Tracheostomy were transferred from ICU, emergency, Trauma, and subspecialty clinic to neurosurgical ward and discharged after receiving educational program during one 7 days to 10 days. The sample was selected using judgmental sampling. In the study, inclusion criteria included the following items:

A person who was in charge of caring patient in home after confinement in the hospital till discharge:

\section{- Willingness to participate in the study}

- Not having any known physical and mental diseases

- Not being professional attentive

\section{- Being literate}

Using interview to complete questionnaires and observation to complete check list, required data was collected. The items of the employed questionnaire were regulated based on the research objectives including two parts of researcher-made (containing demographic information such as age, gender, marital status, education, etc.) and standard Spill Berger anxiety inventory (containing 40 items). In Spill Berger questionnaire, questions 1-20 measure state anxiety or the anxiety of individual during taking test and question 21 to 40 evaluate trait anxiety, as individual and trait of the sample. Total score obtained from the questionnaire is $40-160$ such that 40 are minimum and 160 is maximum. In the study, based on the minimum and maximum score, the anxiety level and the patients' anxiety level was divided into three levels of mild anxiety (40-79), moderate anxiety (80-119) and intense anxiety (12-160). To investigate the performance of family of the patients with Tracheostomy, check list was used. Both check list and questionnaire were completed, observed and recorded by the researcher once in the first 24 hours of confinement in the ward. After 10-14 days of confinement in the ward and teaching the families during discharge, the anxiety inventory (through interview) and check list (through observation) were completed and the results of before and after the education were compared. Educational program was performed theoretically (during two 45-minute sessions through lecture and query) and practically (during three 45-minute individual meetings) with presenting an educational booklet to the sample to study. To evaluate the validity of the first part of the questionnaire and check list, content validity was used and to evaluate the reliability of the check list, interrupter 
Citation: Shiva S, Beheshte T, Osmavandani MM (2017) The Effect of Educational Program on Status Care in Patients with Tracheostomy and Families' Anxiety After Discharge. J Infect Dis Med 2: 118. doi:10.4172/2576-1420.1000118

Page 3 of 5

evaluation method was employed. Therefore, the performance of the patients' families was simultaneously observed by the researcher and anther nurse who was at the same level of education and job experience and its reliability was computed $85 \%$. To analyse the obtained data, descriptive statistics (frequency tables, chart, percentage, mean, and standard deviation) and inferential statistics (paired t-test) were applied through SPSS-19 software.

\section{Findings}

Demographic information of the sample shows that most of the sample is consisted of women (54.8\%), the age range of above 40 years
(58.1\%) and mothers (29\%). Also, monthly income of the families is above 166 dollars (51.6\%); most of the families are literate $(51.6 \%)$; most of the families live with the patient in the same home $(80.6 \%)$ or city (61.3\%); $32.3 \%$ is housewife and $87.1 \%$ of them are married. The cost of caring most of the patients has been paid through insurance and a part of the cost has been paid by the patient himself/herself (Table 1).

\begin{tabular}{|c|c|c|c|}
\hline Variable & Demographic Characteristics & Frequency & Percentage \\
\hline Gender & Female & 17 & $8 / 54$ \\
\hline Age & $>40$ & 18 & $1 / 58$ \\
\hline Kinship & Mother & 9 & 29 \\
\hline Monthly income & Above 166 dollars & 16 & $6 / 51$ \\
\hline Education & Literate & 16 & $6 / 51$ \\
\hline $\begin{array}{l}\text { Living with the patient in the same } \\
\text { home }\end{array}$ & Yeas & 25 & $6 / 80$ \\
\hline Occupation state & Housewife & 10 & $3 / 32$ \\
\hline Marital state & Married & 27 & $1 / 87$ \\
\hline
\end{tabular}

Table 1: Absolute and relative frequency distribution of the sample's demographic characteristics in the patients' families.

The findings obtained from before the education indicate that in terms of manifest anxiety distribution, the most of the sample $(70.97 \%)$ have intense anxiety and the least of them (3.23\%) have mild anxiety before the education. The mean of manifest anxiety in the sample is 61.77 with the standard deviation of 9.58. In terms of latent anxiety, $80.65 \%$ of the sample has moderate anxiety and $6.45 \%$ of them have mild anxiety before the education. The mean of latent anxiety in the sample is 50.58 with the standard deviation of 7.42 . In terms of total anxiety, $70.97 \%$ of the sample has moderate anxiety and $3.23 \%$ of them have mild anxiety before the education. Total anxiety mean of the sample is 112.35 with the standard deviation of 16.18 .
According the findings obtained from after the educational program, in terms of manifest anxiety distribution, $87.1 \%$ of the sample has moderate anxiety and $6.45 \%$ of them have mild anxiety. The mean of manifest anxiety in the sample is 50.64 with the standard deviation of 6.61 . In terms of latent anxiety, $77.4 \%$ of the sample has moderate anxiety and $6.45 \%$ of them have intense anxiety after the educational program. The mean of latent anxiety in the sample is 45.16 with the standard deviation of 6.98 . In terms of total anxiety, $80.65 \%$ of the sample has moderate anxiety and $6.45 \%$ of them have intense anxiety after the treatment. Total anxiety mean of the sample is 95.8 with the standard deviation of 13.7 (Table 2).

\begin{tabular}{|l|l|l|l|l|l|}
\hline \multirow{2}{*}{ Total Anxiety Level } & \multicolumn{2}{|l|}{ Before the Education } & \multicolumn{2}{l|}{ After the Education } & Statistical Estimation \\
\cline { 2 - 5 } & Frequency & Percentage & Frequency & Percentage & \\
\hline Mild (40-79) & 1 & $23 / 3$ & 4 & $9 / 12$ & $\mathrm{P}=0.0001$ \\
\hline Moderate (80-119) & 22 & $97 / 70$ & 25 & $65 / 80$ & $\mathrm{t}=16.29$ \\
\hline Intense (120-160) & 8 & $80 / 25$ & 2 & $45 / 6$ & \\
\hline Total & 31 & 100 & 31 & 100 & \\
\hline $\begin{array}{l}\text { Mean and Standard } \\
\text { Deviation }\end{array}$ & $35 / 112$ & & $8 / 95$ & & \\
\hline
\end{tabular}

Table 2: The comparison of absolute and relative frequency distribution based on total anxiety before and after the educational program in the patients' families. 
Page 4 of 5

Using paired t-test, the mean score of each of manifest, latent and total anxiety questionnaires before and after the educational program have been compared. As shown in Figure 1, manifest, latent and total anxieties have been significantly decreased after the education $(\mathrm{P}=0.0001)$.

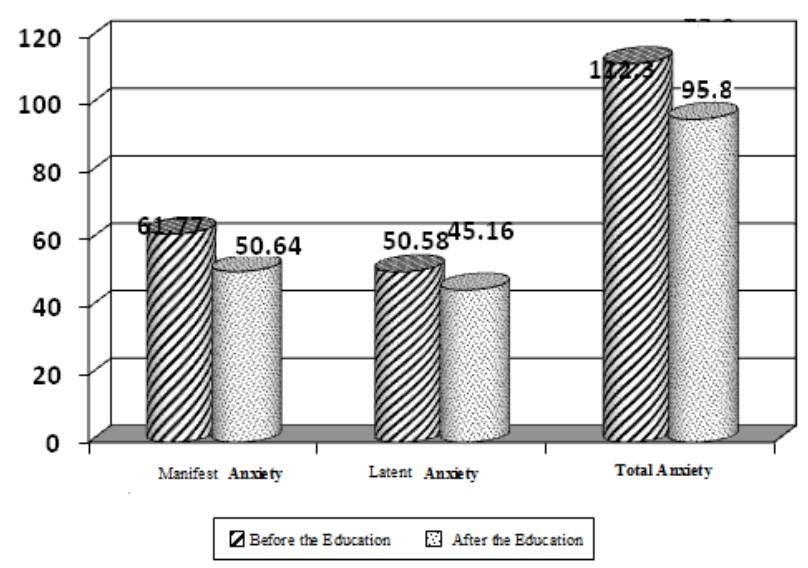

Figure 1: The comparison of the mean scores obtained from manifest, latent and total anxiety questionnaire before and after the educational program in the patients' families.

Compared to the performance of the patients' families, the results of paired $\mathrm{t}$-test reveal that regarding the mean the performance of the sample before and after the educational program, there is a significant difference between the scores of each of performance and total performance check list. In other words, the mean and standard deviation of total performance of the sample has reached from $93.7 \pm$ 6.57 (before the education) to $119 \pm 7.2$ (after the education). That is, shown in Table 3, the performance in each of areas and total performance after the education has been significantly increased relative to before the education $(\mathrm{P}=0.0001)$.

\section{Discussion}

Implementing an educational program which is based on the needs of the families of the patients with Tracheostomy, the present study attempted to find the effects of education on the decrease of the patients' families' anxiety. According to the research findings, total anxiety of the sample before the education was moderate and it was decreased but remained after the education. If the nurses honestly answer the questions of patients' families regarding education, trust and calmness will be increased in the families and their anxiety is decreased. Nurses should support and teach families to prevent emotional problems [15]. In another study, it was revealed that being confined in hospital can be a stressful factor for the families and relatives of patients [6].

Also, a study reported that $75.5 \%$ of the families of patients confined in hospital suffer from anxiety [7]. This finding is consistent with the findings of the present study.

\begin{tabular}{|c|c|c|c|c|c|c|}
\hline Area & Time & Number & Mean & Standard deviation & $\mathrm{t}$-value & $\begin{array}{l}\text { Statistical } \\
\text { Estimation }\end{array}$ \\
\hline \multirow{2}{*}{$\begin{array}{l}\text { Caring Tracheostomy } \\
\text { pipe }\end{array}$} & Before the Education & 31 & 29/14 & $13 / 2$ & \multirow{2}{*}{$8 / 21$} & \multirow{2}{*}{$P=0001 / 0$} \\
\hline & After the Education & 31 & $45 / 20$ & $38 / 1$ & & \\
\hline \multirow[t]{2}{*}{ Caring during suction } & Before the Education & 31 & $41 / 34$ & $94 / 3$ & \multirow{2}{*}{$3 / 16$} & \multirow{2}{*}{$P=0001 / 0$} \\
\hline & After the Education & 31 & $8 / 43$ & $46 / 3$ & & \\
\hline \multirow{2}{*}{$\begin{array}{l}\text { Caring during chest } \\
\text { physiotherapy }\end{array}$} & Before the Education & 31 & $12 / 14$ & $64 / 1$ & \multirow{2}{*}{$6 / 10$} & \multirow{2}{*}{$P=0001 / 0$} \\
\hline & After the Education & 31 & $74 / 17$ & $92 / 0$ & & \\
\hline \multirow{2}{*}{$\begin{array}{l}\text { Caring during oxygen } \\
\text { therapy }\end{array}$} & Before the Education & 31 & $7 / 14$ & $1 / 1$ & \multirow{2}{*}{$3 / 12$} & \multirow{2}{*}{$P=0001 / 0$} \\
\hline & After the Education & 31 & $03 / 17$ & $42 / 1$ & & \\
\hline \multirow{2}{*}{$\begin{array}{l}\text { Caring moth and teeth } \\
\text { health }\end{array}$} & Before the Education & 31 & $16 / 16$ & $34 / 1$ & \multirow{2}{*}{$5 / 12$} & \multirow{2}{*}{$P=0001 / 0$} \\
\hline & After the Education & 31 & $83 / 20$ & $06 / 2$ & & \\
\hline \multirow{2}{*}{$\begin{array}{l}\text { Total performance } \\
\text { questionnaire }\end{array}$} & Before the Education & 31 & $7 / 93$ & $57 / 6$ & \multirow{2}{*}{$2 / 30$} & \multirow{2}{*}{$P=0001 / 0$} \\
\hline & After the Education & 31 & $8 / 119$ & $2 / 7$ & & \\
\hline
\end{tabular}

Table 3: The comparison of the mean of the patients' families' performance before and after the educational program.

In the present research, teaching to care Tracheostomy influenced the level of the patients' families' anxiety. The highest level of manifest anxiety before the education was intense and after the education, this level was decreased to moderate level. Also, the highest level of latent and total anxiety before the education was at moderate level and after the education, this level was highly decreased. Meeting the needs of patients' families and decreasing their anxiety is the duty of all healthcare team and nurses have an especial place and in fact, they are the main support of patients' families in hospital [27]. Accordingly, education significantly decreases anxiety. Such a finding is consistent with the finding reported in 2007 by a study investigating the stress of 
families before teaching the sample, high stress and moderate stress after the treatment $(\mathrm{P}=0.0001)[24]$.

Moreover, teaching to care Tracheostomy influences the level of performance of patients' families. Anxiety in families can disturb the role and performance of family, increase their economic and social problems and collapse the main structure of this small society. Obviously, when one member of the family suffers from an intense disease, the responsibility of other members of the family is increased and understanding such an issue causes anxiety for the family [28]. Totally, the research findings indicated that providing families of the patients with Tracheostomy with comprehensive education to decrease their anxiety and increase their performance level is vital in caring patients and should be seriously considered by nursing personnel together with implementing appropriate interventions.

\section{Conclusion}

The findings of the present project can attract the attention of authorities and planners of nursing, coaches and students regarding clinical, management and education areas as well as public health to the important principle of anxiety and the necessary diagnosis, control, prevention, and teaching methods regarding teaching caring to families.

\section{Acknowledgment}

All the respected personnel of neurosurgery ward and all respected families participated in this study are highly appreciated.

\section{References}

1. Janbozorgi M, Nouri N (2004) Anxiety and stress psychotherapy. Tehran Samt Publishing, Tehran.

2. Basampoor SH (2006) The effect of preoperative education on anxiety of patients undergoing open heart surgery. Tehran J Health Sci 3: 10-15.

3. Lampic C, von Essen L, Peterson VW, Larsson G, Sjödén PO (2006) Anxiety and depression in hospitalized patients with cancer. Cancer Nursing 19: 419-428.

4. Maxwell KE, Stuenkel D, Saylor C (2008) Needs of family members of critically ill patients: A comparison of nurse and family perception. Heart \& Lung 36: 367-376.

5. koshan M, Vaghei S (2009) Psychiatric mental health. Tehran Rafie Publishing, Tehran. p. 48.

6. Pochard F, Darmon M, Fassier T, Bollaert PE, Cheval C, et al. (2006) Symptoms of anxiety and depression in family members of intensive care unit patients before discharge or death. J Crit Care 20: 90-96.

7. Siahkali SR, Pourmemari MH, Mohammadi TK, Askandari F, Avazeh A (2010) Study of effective factors in patient families anxiety in the intensive care unit. J Zanjan Medical University 18: 91-101.
8. Videbeck SL (2011) Psychiatric mental health nursing. Lippincott Co, Philadelphia. p. 141.

9. Chui WY, Chain SC (2007) Stress and coping of Hongkong family members during a critical illness. J Clin Nurs 16: 372-381.

10. Potter P, Perry A (2012) Basic nursing: Essential for practice (6th edn.). C.V. Mosby, St Louis. pp: 27-82.

11. Bartelmo S (2006) Medical surgical nursing related nephrology (7th edn.). C.V. Mosby, Philadelphia.

12. Taylor C (2007) Foundamental in nursing the art and science of nursing care. Lippencott Williams and Wilkins, Philadelphia.

13. Cristensen, Kockvow (2006) Foundation and adult health nursing. Lippencott Williams and Wilkins, Philadelphia.

14. Hickey JV (2008) The clinical practice of neurological \& nursing. Lippencott Williams and Wilkins, Philadelphia.

15. Freitas KS, Kimura M, Fevveira KASL (2009) Family members need at intensive care unit: comparative analysis between a public and a private hospital. Rev Latino-Am Enfermagem 15: 84-92.

16. Zahed H, Arbaby SH, Soltani A (2010) Assessment preoperation and control airway in condition elective and emergency. Journal of Tehran Medical University.

17. Hermes C, Grillo MD (2006) Surgery of the trachea and bronchi. Bc Decker Inc. Hamilton, London.

18. Khatoni (2011) Procedure of clinical nursing. Tehran Jamea Negar Publishing, Tehran.

19. Fischler L, Erhart S, Kleger GR, Frutiger A (2006) Prevalence of tracheostomy in ICU patients. A nation-wide survey in Switzerland. Intensive Care Med 26: 1428-1433.

20. Kluge S, Baumann HJ, Maier C Klose H, Meyer A, et al. (2008) Tracheostomy in the intensive care unit: A national wide survey. Anesth Analg 107: 163-173.

21. Sabori M, Taromsary M, Hosseini B (2010) The effect of early tracheostomy in patients with head injury on result treatment. Journal of Esfahan Medical University.

22. Wilson M (2006) Tracheostomy management. Pediatr Nurs 17: 38-43.

23. Smeltzer S, Bare B (2010) Text book of medical surgical nursing (12th edn). Lippencott Williams and Wilkins, Philadelphia.

24. Chien WT, Chui YL, Lam LW, IP WY (2006) Effects of a needs-based education programme for family attentive with a relative in an intensive care unit: A quasiexperimental study. Int J Nurs Stud 43: 39-50.

25. El-Masri MM, Fox-Wasylyshyn SM (2009) Nurses' roles with families: Perceptions of ICU nurses. Intensive Crit Care Nurs 23: 43-50.

26. Sheich BA (2010) Education mental health in attentive head injury patients after the discharge. Mashhad medical university. pp: 56-70.

27. Bucher L, Melander S (2008) Critical care nursing. Saunders Co., New Zealand.

28. Bahrami $\mathrm{F}$ (2010) The efficacy of education on stress in patients family in intensive care unit. Esfahan Medical University, Iran. pp: 37-38. 